CHRONIC OBSTRUCTIVE PULMONARY DISEASE

\title{
Relationship between peripheral airway dysfunction, airway obstruction, and neutrophilic inflammation in COPD
}

\author{
R A O'Donnell, C Peebles, J A Ward, A Daraker, G Angco, P Broberg, S Pierrou, J Lund, \\ S T Holgate, D E Davies, D J Delany, S J Wilson, R Djukanovic
}

Thorax 2004;59:837-842. doi: 10.1136/thx.2003.019349

See end of article for authors' affiliations

Correspondence to:

Dr R O'Donnell

Respiratory Cell and Molecular Biology,

Division of Infection

Inflammation and Repair,

University of Southampton,

Southampton General

Hospital, Southampton

SO16 6YD, UK

raodonnell@eircom.net

Received

26 November 2003

Accepted 22 July 2004
Background: Considerable research has been conducted into the nature of airway inflammation in chronic obstructive pulmonary disease (COPD) but the relationship between proximal airways inflammation and both dynamic collapse of the peripheral airways and HRCT determined emphysema severity remains unknown. A number of research tools have been combined to study smokers with a range of COPD severities classified according to the GOLD criteria.

Methods: Sixty five subjects ( 11 healthy smokers, 44 smokers with stage 0-IV COPD, and 10 healthy nonsmokers) were assessed using lung function testing and HRCT scanning to quantify emphysema and peripheral airway dysfunction and sputum induction to measure airway inflammation.

Results: Expiratory HRCT measurements and the expiratory/inspiratory mean lung density ratio (both indicators of peripheral airway dysfunction) correlated more closely in smokers with the severity of airflow obstruction $(r=-0.64, p<0.001)$ than did inspiratory HRCT measurements (which reflect emphysema severity; $r=-0.45, p<0.01$ ). Raised sputum neutrophil counts also correlated strongly in smokers with HRCT indicators of peripheral airway dysfunction $(r=0.55, p<0.001)$ but did not correlate with HRCT indicators of the severity of emphysema.

Conclusions: This study suggests that peripheral airway dysfunction, assessed by expiratory HRCT measurements, is a determinant of COPD severity. Airway neutrophilia, a central feature of COPD, is closely associated with the severity of peripheral airway dysfunction in COPD but is not related to the overall severity of emphysema as measured by HRCT.

\footnotetext{
C
} hronic obstructive pulmonary disease (COPD) develops in smokers as a result of a combination of varying degrees of peripheral airway remodelling and emphysema, both of which are associated with airway inflammation and distortion of the pulmonary vascular morphology. ${ }^{1-3}$ The study of surgical and post-mortem samples has provided an insight into parenchymal and small airway changes ${ }^{4-7}$ while high resolution computed tomography (HRCT) density mask analysis has enabled non-invasive quantitation of emphysema, showing that it correlates with the pathological changes seen in tissue samples. ${ }^{89}$ Complementing these studies, bronchial biopsy, bronchoalveolar lavage (BAL) and, more recently, induced sputum analysis have been used to describe a number of pathological features such as infiltration of the airways with neutrophils, ${ }^{10}$ macrophages, ${ }^{11}$ and $\mathrm{CD} 8+\mathrm{T}$ cells $^{12}$ as being typical of COPD.

Despite the availability of induced sputum (to analyse large airway inflammation) and objective HRCT indicators of lung density which provide measurements of emphysema and peripheral airways dysfunction, no studies have combined these approaches to see whether there is any relationship between proximal airway inflammation and distal airway changes.

In this study we combined a number of validated methods to study subjects from a wide clinical spectrum of COPD. We correlated lung function measurements, as an index of disease severity, with expiratory HRCT densitometry measurements and the expiratory/inspiratory mean lung density ratio (E/I ratio), which are affected by peripheral airway obstruction and air trapping,,$^{13-17}$ and inspiratory HRCT measurements which reflect the extent of emphysematous destruction. ${ }^{8}{ }^{9}$ We then sought to relate the type and intensity of large airway inflammation (as assessed in induced sputum) to the severity of small airways dysfunction and emphysema (as determined by HRCT).

\section{METHODS}

The study was approved by the Southampton University and General Hospitals ethics committee. Volunteers were prospectively recruited for the purpose of the study and gave their written informed consent.

\section{Clinical assessment and classification by disease severity}

A detailed clinical history was taken and physical examination performed. Lung function testing consisted of spirometry, carried out according to the ATS guidelines, ${ }^{18}$ flow-volume loop with flow rate measurements at 50\% expiration $\left(\mathrm{MEF}_{50}\right)$, measurement of the ratio of residual volume to total lung capacity (RV/TLC), and carbon monoxide gas transfer coefficient (KCO) and factor (TLCO). Bronchodilator responsiveness to $400 \mu \mathrm{g}$ salbutamol was assessed and post-bronchodilator spirometric values were recorded. Histamine bronchial provocation challenge was carried out as reported previously. ${ }^{19}$

Based on clinical assessment and HRCT scanning, a total of 65 subjects were enrolled and classified into five groups according to the GOLD criteria: ${ }^{20}(1)$ healthy control subjects $(\mathrm{n}=10)$ with normal lung function and no emphysema;

\footnotetext{
Abbreviations: COPD, chronic obstructive pulmonary disease; E/I ratio, expiration/inspiration ratio; $\mathrm{FEV}_{1}$, forced expiratory volume in 1 second; FVC, forced vital capacity; HRCT, high resolution computed tomography; KCO, lung carbon monoxide transfer coefficient; LAA, area of low attenuation; MEF, mid expiratory flow; MLD, mean lung density; $\mathrm{RV}$, residual volume; TLC, total lung capacity; TLCO, carbon monoxide lung transfer factor.
} 
(2) healthy smokers $(n=11)$ without chronic bronchitis and emphysema (as judged by the radiologists' (CP and DJD) interpretation of their HRCT scan) and with normal lung function; (3) stage 0 COPD $(n=17)$-that is, smokers with cough and sputum production but normal spirometry; (4) stage I COPD $(\mathrm{n}=10)$ with mild airflow limitation (forced expiratory volume in 1 second $\left(\mathrm{FEV}_{1}\right)>80 \%$ of predicted, and $\mathrm{FEV}_{\mathrm{l}}$ /forced vital capacity (FVC) $<70 \%$ ); and (5) stage II-IV COPD $(\mathrm{n}=17)$ with moderate to severe airflow obstruction $\left(\mathrm{FEV}_{1}<80 \%\right.$ and $\mathrm{FEV}_{1} / \mathrm{FVC}<70 \%$ (table 1 )). Of the 17 subjects with stage II-IV COPD, 12 were stage II, three were stage III, and two were stage IV. None of the volunteers was atopic and none showed significant bronchodilator reversibility (either $>15 \%$ of baseline $\mathrm{FEV}_{1}$ or $>200 \mathrm{ml}$ ). Five subjects with more severe COPD did not undergo histamine bronchial provocation challenge as their baseline $\mathrm{FEV}_{1}$ was too low $(<50 \%)$. All of the other subjects had normal responsiveness to histamine. All had been free of chest infections and in all cases sputum microbiological culture results were negative with no evidence of bacterial infection of the airways. No subject had had oral corticosteroid therapy for at least 3 months. Furthermore, none had ever been on inhaled corticosteroids.

\section{HRCT}

HRCT scanning was used for the evaluation of both emphysema and peripheral airways dysfunction. Scans (Hispeed CTi scanner, General Electric) were performed on full inspiration and expiration at $10 \mathrm{~mm}$ intervals with a collimation (slice thickness) of $1 \mathrm{~mm}$. The scanner was subject to a weekly quality assessment with a phantom check including uniformity, linearity, and noise. In addition there was a 3 monthly engineering check of spatial and contrast resolution and an annual medical physics check. Scanning voltage was $140 \mathrm{kV}$ and current was $250 \mathrm{~mA}$. Hard copy images were photographed at a window level of $-650 \mathrm{HU}$ and a window width of $1500 \mathrm{HU}$, as appropriate for viewing lung parenchyma. The scans were evaluated for the presence of emphysema both qualitatively by two radiologists independently of the remaining research and quantitatively by computerised density mask analysis. Two lung density parameters were measured: \% area of low attenuation (\% LAA) with low attenuation being defined as $<-950$ Hounsfield density units, ${ }^{9}$ and mean lung density (MLD)that is, the mean attenuation value of all voxels excluding the mediastinum and trachea. Peripheral airways dysfunction and expiratory gas trapping were assessed radiologically by calculating the ratio of the MLD on expiration to MLD on inspiration (E/I ratio), as described in previous studies. ${ }^{15} 16$

\section{Assessment of airway inflammation}

Airway inflammation was assessed in induced sputum. Sputum induction was carried out as previously reported. ${ }^{21}$ Cytospins were made, coded, and differential cell counting was performed on 600 cells. Results are shown as absolute and relative counts (percentage of non-squamous inflammatory cells). In addition, sputum samples were sent for microbiological culture to allow exclusion of subjects with detectable bacterial infection of the airways.

\section{Data analysis}

Statistical analysis was performed using SPSS version 10.0. Normally distributed data (lung function and HRCT) were compared between multiple groups by ANOVA, followed by the Scheffe examination for individual comparisons. Cell counts in sputum were compared using the Kruskal-Wallis test followed by the Mann-Whitney test. Trend analysis for the clinical groups was performed using the JonckheereTerpstra test. Correlations were sought by Pearson's and Spearman's tests for normally and non-normally distributed data, respectively. Correction for multiple correlations was

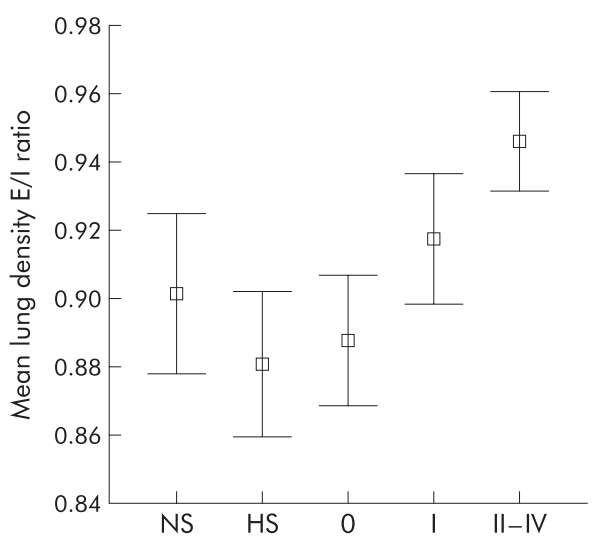

Figure 1 Lung density expiratory/inspiratory (E/I) ratio in non-smokers (NS), healthy smokers (HS), and patients with stage 0,1 , and II-IV COPD. The ratio was significantly higher in smokers with airflow obstruction than in healthy smokers, patients with stage 0 COPD, and non-smokers. Values are expressed as means with standard deviation.

Table 1 Clinical characteristics and HRCT measurements performed on inspiration and expiration of the five subject groups

\begin{tabular}{|c|c|c|c|c|c|c|}
\hline & $\begin{array}{l}\text { Non-smokers } \\
(n=10)\end{array}$ & $\begin{array}{l}\text { Healthy smokers } \\
(n=11)\end{array}$ & $\begin{array}{l}\text { Stage } 0 \text { COPD } \\
(n=17)\end{array}$ & $\begin{array}{l}\text { Stage I COPD } \\
(n=10)\end{array}$ & $\begin{array}{l}\text { Stage II-IV COPD } \\
(n=17)\end{array}$ & $\begin{array}{l}\text { p value } \\
\text { (ANOVA) }\end{array}$ \\
\hline Age (years) & $51(7)$ & 45 (12) & $50(7)$ & $57(7)$ & $55(7)$ & \\
\hline Pack years & $0 \ddagger$ & 40 (15)† & 43 (19)t * & $44(13) \dagger^{*}$ & $52(14)^{*}$ & $<0.001$ \\
\hline SGRQ & $4.7(12.2) \dagger$ & $7.1(5.0) \dagger$ & $20.4(16.1) \dagger^{*}$ & $27.2(12.9)^{*}$ & $35.3(19.7)^{*}$ & $<0.001$ \\
\hline $\mathrm{FEV}_{1}(\%)$ & $111(12.2) \ddagger$ & 102 (8)‡† & 99 (14)‡† & $91(6) \dagger$ & $56(16)^{*}$ & $<0.001$ \\
\hline $\mathrm{FEV}_{1} / \mathrm{FVC}$ & $77(5.4) \ddagger$ & 80 (5)‡† & 75 (3)‡ & $66(3) \dagger$ & $55(12)^{*}$ & $<0.001$ \\
\hline $\mathrm{MEF}_{50 \%}$ & 85 (17.5) & $85(23) \ddagger$ & $76(22.1) \ddagger$ & $48(9) \dagger$ & $24(12.6)^{*}$ & $<0.001$ \\
\hline $\mathrm{RV} / \mathrm{TLC}$ & $30(3.5) \dagger$ & $28.7(7.1) \dagger$ & $35(7.7) \dagger$ & $38(5.2) \dagger^{*}$ & $49(7.9)^{*}$ & $<0.001$ \\
\hline $\operatorname{TLCO}(\%)$ & $84(12.1) \ddagger$ & $74(12) \ddagger \dagger$ & $63(10) \dagger$ * & $65(18) \dagger^{*}$ & $56(16)^{*}$ & $<0.001$ \\
\hline KCO $(\%)$ & $82(12.6) \dagger$ & $67(14)^{*}$ & $61(13)^{*}$ & $62(19)^{*}$ & $64(15)^{*}$ & $<0.01$ \\
\hline Inspiratory MLD (HU) & $-840(27)$ & $-825(25)$ & $-824(19)$ & $-852(23)$ & $-846(25)$ & \\
\hline Inspiratory \%LAA & $8.9(4.3)$ & $7.0(3.2)$ & $5.8(2.7)$ & $12.6(8.1)$ & $11.4(7.4)$ & \\
\hline Expiratory MLD (HU) & $-755(44) \dagger^{*}$ & -727 (45)† & $-732(35) \dagger$ & $-783(36)^{*}$ & $-801(38)^{*}$ & $<0.01$ \\
\hline Expiratory \%LAA & $3.3(2) \dagger^{*}$ & $2.7(1.6) \dagger$ & $2.3(1) \dagger$ & $7.1(6.4)^{*}$ & $7.3(6.8)^{*}$ & $<0.01$ \\
\hline $\mathrm{E} / \mathrm{I}$ ratio & $0.89(0.03) \dagger$ & $0.88(0.04) \dagger$ & $0.88(0.03) \dagger$ & $0.91(0.02) \dagger^{*}$ & $0.94(0.02)^{*}$ & $<0.001$ \\
\hline
\end{tabular}

All data are shown as mean (SD). * † $\ddagger$ Homogenous Scheffe subsets.

$\mathrm{SGRQ}$, St George's Respiratory questionnaire; $\mathrm{FEV}_{1}$, forced expiratory volume in 1 second; FVC, forced vital capacity; MEF, mid expiratory flow; KcO, lung carbon monoxide transfer coefficient; TLCO, carbon monoxide lung transfer factor; MLD, mean lung density; LAA, area of low attenuation; E/I ratio, expiration/ inspiration ratio. 
carried out using the Holm method, ${ }^{22}$ which is a modification of the Bonferroni method but has higher power at the same type I error rate. Thus, if $p_{j}$ is the $p$ value corresponding to variable $\mathrm{j}$ and there are $\mathrm{k}$ variables (hypotheses) to test, the Holm method consists of multiplying the $\mathrm{j}^{\text {th }}$ smallest $\mathrm{p}$ value by $\mathrm{k}-\mathrm{j}+1$. p values $<0.05$ were regarded as significant.

\section{RESULTS}

The five subject groups were matched for age. Although the three COPD groups were matched for the number of pack years, smokers with stage II-IV COPD had a significantly greater pack year history than healthy smokers (table 1). The TLCO was significantly reduced in all three COPD groups compared with non-smokers and in patients with stage II-IV COPD compared with healthy smokers also. Kco measurements were lower in all smoking groups than in non-smokers but did not differ significantly between smoking groups. Using the Jonckheere-Terpstra test, a significant trend was observed for the TLCO, but not the KCO, to fall with advancing disease stage $(\mathrm{p}<0.001$, table 1$)$.

\section{Appraisal of HRCT scans by radiologists}

None of the healthy non-smokers and, by definition, the healthy smokers had emphysema on HRCT scans as assessed by the radiologists. In contrast, $11 / 17$ subjects with stage 0 COPD, 7/10 subjects with stage 1 COPD, and 11/17 with stage II-IV COPD were identified as having HRCT evidence of emphysema. The amount of emphysema in all 11 cases of stage 0 COPD was described as minimal $(<5 \%$ of total lung area) while in stage I and II-IV disease the extent of emphysema ranged from minimal to severe $(>30 \%$ of total lung area).

\section{Computerised density mask analysis of HRCT}

The comparison of \%LAA and MLD by ANOVA (allowing for multiple comparisons) showed significant differences between the groups only when comparing expiratory HRCT measurements. Post hoc analysis using the Scheffe test showed no differences between non-smokers and any of the smoker groups for expiratory HRCT measurement (\%LAA and MLD; table 1), while the E/I ratio was significantly higher in patients with stage II-IV COPD than in nonsmokers, healthy smokers, and those with stage 0 COPD (table 1 and fig 1). Further comparison of \%LAA on expiration showed a significant increase in both stages I and II-IV COPD compared with both healthy smokers and patients with stage 0 COPD (table 1). Moreover, MLD on expiration was significantly reduced in patients with stage IIIV COPD compared with healthy smokers and those with stage 0 COPD, and in stage I COPD compared with healthy smokers (table 1).

When smoking related trends in HRCT densitometry were analysed in the four smoking groups in isolation using the Jonckheere-Terpstra test, significant trends were observed for \%LAA to rise and MLD to fall with advancing disease stage on

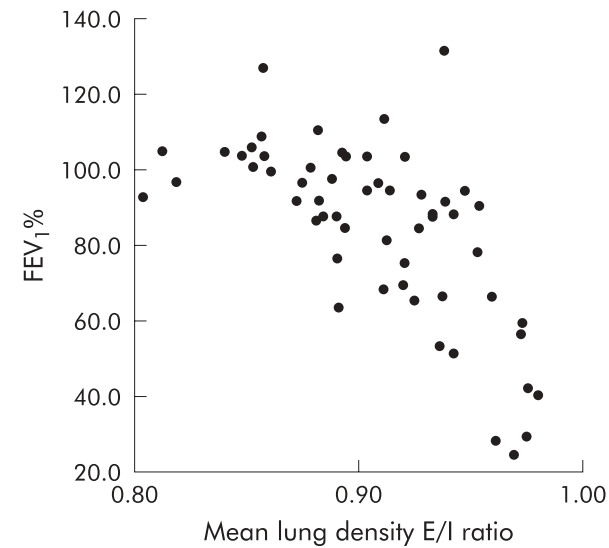

Figure 2 Relationship between the lung density $\mathrm{E} / \mathrm{I}$ ratio and $\mathrm{FEV}, \%$ predicted $(r=-0.66, \mathrm{p}<0.001)$.

both inspiration and expiration $(\mathrm{p}<0.001$ in all cases $)$. There was also a significant trend for the E/I ratio to rise with advancing disease stage $(\mathrm{p}<0.001)$.

\section{Correlations between HRCT and lung function}

Lung function correlated moderately strongly with HRCT parameters (table 2). The strongest correlations seen in smokers were between the E/I ratio on the one hand and airway obstruction ( $\mathrm{FEV}_{1} \%$ predicted; fig 2$)$, mid expiratory flow $\left(\mathrm{MEF}_{50}\right)$, and gas trapping (RV/TLC) on the other, with no correlation being seen with TLCO or KCo. Strong and highly significant correlations were also observed between MLD and $\mathrm{FEV}_{1}, \mathrm{MEF}_{50}$, and RV/TLC but not either TLCO or KCO. These correlations were stronger on expiration than inspiration. Both expiratory and inspiratory \%LAA correlated weakly to moderately strongly with $\mathrm{FEV}_{1}$ and RV/TLC but also, albeit weakly, with TLCo but not at all with Kco. These correlations were only marginally stronger on expiration.

\section{Assessment of airway inflammation}

No significant differences were observed between any of the groups with regard to the total numbers of cells in induced sputum. The only cell counts that were different between the groups were the relative counts of neutrophils and macrophages. Relative neutrophil counts were significantly higher in stage II-IV COPD than in all other groups (table 3 ). The relative macrophage counts followed a reciprocal pattern to the neutrophils, being significantly reduced in stage II-IV COPD compared with all the other groups. Despite the absence of significantly increased absolute neutrophil counts, significant trends were observed using the JonckheereTerpstra tests for both relative $(p=0.001)$ and absolute $(\mathrm{p}=0.007)$ neutrophil counts to rise with advancing disease stage (table 3 ).

Table 2 Correlation in smokers between HRCT measurements performed on inspiration and expiration and lung function

\begin{tabular}{|c|c|c|c|c|c|}
\hline \multirow[b]{2}{*}{ Functional variable } & \multicolumn{5}{|c|}{ Correlation coefficient $(r)$} \\
\hline & Expiratory \%LAA & Inspiratory \%LAA & Expiratory MLD & Inspiratory MLD & E/I ratio \\
\hline $\begin{array}{l}\mathrm{FEV}_{1}(\%) \\
\mathrm{RV}^{\prime} \mathrm{TLC} \\
\mathrm{MEF}_{50}(\%) \\
\mathrm{TLCO}_{(\%)} \\
\text { KCO }(\%)\end{array}$ & $\begin{array}{l}-0.52 \\
0.47(p<0.01) \\
-0.51 \\
-0.42(p<0.01) \\
0.10(p>0.05)\end{array}$ & $\begin{array}{l}-0.45(p<0.01) \\
0.38(p<0.05) \\
-0.46 \\
-0.36 \\
-0.01(p>0.05)\end{array}$ & $\begin{array}{l}0.63 \\
-0.69 \\
0.72 \\
0.25(p>0.05) \\
-0.06(p>0.05)\end{array}$ & $\begin{array}{l}0.38(p<0.01) \\
-0.43(p<0.01) \\
0.46 \\
0.1(p>0.05) \\
-0.18(p>0.05)\end{array}$ & $\begin{array}{l}-0.64 \\
0.71 \\
-0.72 \\
-0.28(p>0.05) \\
-0.03(p>0.05)\end{array}$ \\
\hline
\end{tabular}

LAA, area of lung attenuation; $M L D$, mean lung density; $\mathrm{FEV}_{1}$, forced expiratory volume in 1 second; RV, residual volume; TLC, total lung capacity; $\mathrm{MEF}_{50}$, mid expiratory flow; TLCO, carbon monoxide transfer factor; KCO, carbon monoxide transfer coefficient. $p<0.001$ unless otherwise stated. 
Table 3 Relative (percentage of non-squamous cells) and absolute (total number of cells $\times 10^{6}$ expectorated over 20 minutes) neutrophil and macrophage counts in induced sputum

\begin{tabular}{llllll}
\hline & Non-smokers & $\begin{array}{l}\text { Healthy } \\
\text { smokers }\end{array}$ & $\begin{array}{l}\text { Stage 0 } \\
\text { COPD }\end{array}$ & $\begin{array}{l}\text { Stage I } \\
\text { COPD }\end{array}$ & $\begin{array}{l}\text { Stage II-IV } \\
\text { COPD }\end{array}$ \\
\hline $\begin{array}{l}\text { Total inflammatory cells } \\
\left(\times 10^{6}\right)\end{array}$ & $1.6(0.9-6)$ & $1.65(0.8-24.7)$ & $2.0(0.95-7.5)$ & $2.8(1.2-5.1)$ & $2.6(1.3-10.6)$ \\
Neutrophils $(\%)$ & $37.6(16.1-47.6)$ & $46.0(30.7-67.9)$ & $50.9(25.1-66.9)$ & $53.9(26.9-70.7)$ & $67.8(44.6-78.1)^{*}$ \\
Neutrophils $\left(\times 10^{6}\right)$ & $776(103-2774)$ & $546(217-4358)$ & $830(233-3692)$ & $1387(482-1986)$ & $1416(789-6485)$ \\
Macrophages $(\%)$ & $55.1(41.9-75.1)$ & $49.5(24.5-68.9)$ & $42.4(30-70.4)$ & $43.4(17.6-59.2)$ & $27.5(10.1-41.5)^{*}$ \\
Macrophages $\left(\times 10^{6}\right)$ & $618(335-3330)$ & $513(91-4195)$ & $871(298-2840)$ & $806(298-2646)$ & $722(203-1941)$ \\
\hline
\end{tabular}

Data are expressed as median (range).

${ }^{*} \mathrm{p}<0.05 v$ all other groups.

Relative neutrophil counts correlated significantly with measurements of airway obstruction and gas trapping $\left(\mathrm{FEV}_{1}\right.$ $\%$ predicted $(r=-0.54, \mathrm{p}<0.001), \mathrm{FEV}_{\mathrm{l}} / \mathrm{FVC}$ ratio $(r=-0.52$, $\mathrm{p}<0.001)$, RV/TLC $(r=0.56, \mathrm{p}<0.001))$ and with the E/I ratio $(r=0.55, \mathrm{p}<0.001$; fig 3). Relative neutrophil counts correlated more strongly with expiratory MLD $(r=-0.59$, $\mathrm{p}<0.001)$ than with inspiratory MLD $(r=-0.42, \mathrm{p}<0.005)$. No significant correlations were observed between relative neutrophil counts and either inspiratory \%LAA or TLCO \% predicted. Absolute sputum neutrophil counts correlated only weakly with the $\mathrm{FEV}_{1} / \mathrm{FVC}$ ratio $(r=-0.36, \mathrm{p}<0.001)$ and with the RV/TLC $(r=0.3, \mathrm{p}<0.05)$ but not with any other lung function or HRCT parameter. Like relative neutrophil counts, no significant correlations were observed between absolute neutrophil counts and either inspiratory \%LAA or TLCO \% predicted.

\section{DISCUSSION}

We have investigated the relationship in COPD between proximal airway inflammation, as judged by induced sputum, and quantitative HRCT measurements of peripheral airway dysfunction and emphysema. The study shows that peripheral airway dysfunction is significantly associated with airflow limitation in mild and moderate COPD, although it does not establish whether this occurs due to small airway remodelling or loss of elastic recoil caused by emphysema. As shown previously, ${ }^{12}{ }^{23}$ sputum neutrophil counts were significantly related to COPD severity. However, the results show for the first time that neutrophil counts are significantly associated with HRCT indices of peripheral airways dysfunction but not with the severity of emphysema.

HRCT is a useful non-invasive tool to assess emphysema. ${ }^{24}$ Its interpretation depends on whether scans are taken on inspiration or expiration. Thus, \%LAA correlates better with emphysematous destruction of the lungs on inspiration ${ }^{8} 9$ while both MLD and \%LAA correlate more closely with functional impairment (airflow obstruction and gas transfer) when analysed during expiration, ${ }^{13}{ }^{14}$ and CT scanning on expiration differentiates better between COPD subjects and healthy controls. ${ }^{17}$ Calculation of the MLD E/I ratio allows indirect evaluation of gas trapping and small airway dysfunction. ${ }^{15}{ }^{16}$ These differences have been explained by the fact that expiratory, but not inspiratory, CT scanning 2526 also reflects peripheral airway dysfunction that causes air trapping. ${ }^{8}{ }^{15}$ 27 By contributing to both airway obstruction and gas trapping, peripheral airway dysfunction is believed to provide an explanation for the stronger correlation between spirometric and expiratory HRCT parameters. ${ }^{14} 1528$

The current study shows that both expiratory HRCT measurements and the MLD E/I ratio correlate more closely with lung function impairment and are more effective in distinguishing smokers with and without airflow obstruction than either inspiratory HRCT, TLCO or KCO. Although the
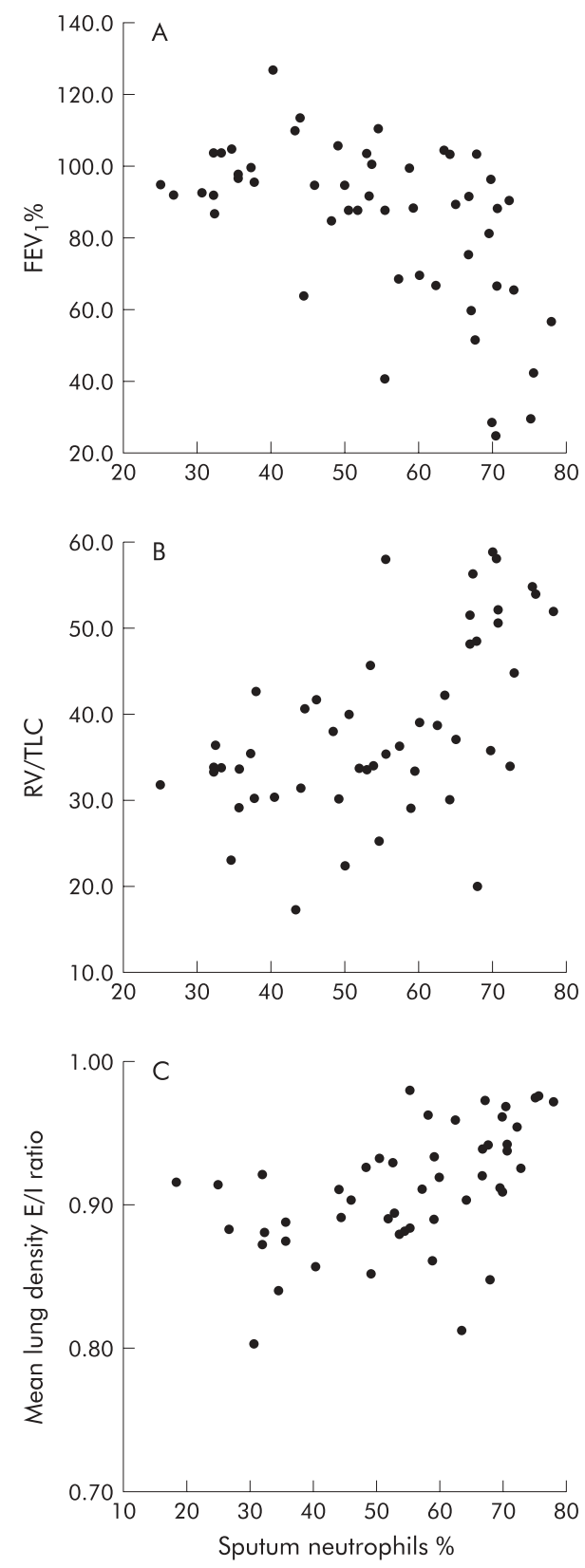

Figure 3 Relationship between relative sputum neutrophil counts and lung function measurements of $(\mathrm{A})$ airflow obstruction ( $\mathrm{FEV}, \%$ predicted: $r=-0.54, p<0.001$ ), (B) gas trapping (RV/TLC: $r=0.56, p<0.001$ ) and $(C)$ the expiratory/inspiratory $(E / I)$ ratio $(r=0.54, p<0.001)$. 
TLCo, which may be affected by peripheral airways obstruction, ${ }^{14}$ displayed a significant downward trend with advancing disease stage and was associated with \%LAA, the Kco, which is more closely related to diffusion impairment, was statistically similar in smokers with and without COPD. The results support the view that small airway dysfunction is a major determinant of reduced lung function in mild to moderate COPD, and a greater predictor of functional impairment than the percentage volume of emphysema as measured by inspiratory \%LAA in the current patients.

Whether peripheral airways dysfunction is principally determined by emphysematous destruction of the lung or small airways remodelling cannot be determined by HRCT scanning because it is not as sensitive as histological analysis of lung tissue and may not be sensitive enough to detect early or mild emphysematous changes that can be seen by pathological examination. ${ }^{24}{ }^{29}$ Even histological assessment has limitations; peripheral airway instability and loss of elastic recoil linked to destruction of alveolar attachments ${ }^{30}$ may be present in smokers without emphysema being detected even by pathological examination. ${ }^{31}$ Thus, subjects with significant airflow limitation may have more parenchymal destruction than can be appreciated by HRCT but which, nonetheless, is contributing to peripheral airway dysfunction.

An important objective of this study was to relate sputum inflammatory cells to airflow limitation and the HRCT indicators of air trapping and emphysema. The finding of raised relative sputum neutrophil counts in COPD is consistent with other studies. ${ }^{32}{ }^{33}$ Importantly, the counts correlated strongly with measurements of peripheral airway obstruction and gas trapping (RV/TLC ratio), MLD on expiration and the E/I ratio but, interestingly, no correlation was observed with either inspiratory \%LAA or TLCO, both indicators of emphysema. Only subjects with moderate to severe COPD had significantly raised neutrophil counts. In keeping with these results, it has previously been shown that, although smokers with very severe emphysema have prominent neutrophilic inflammation in the alveolar walls and air spaces, ${ }^{6}$ smokers with mild emphysema without airflow obstruction have neither $\mathrm{BAL}^{34}$ nor alveolar neutrophilia. ${ }^{6}$ Our results therefore suggest that relative sputum neutrophil counts in smokers are of much greater clinical relevance as an indicator of peripheral airways dysfunction than of emphysema detected by HRCT scanning. We speculate that increased relative sputum neutrophil counts reflect the more distal neutrophilic inflammation that is associated with bronchiolitis and/or destruction of peripheral airway alveolar attachments. To what degree, however, the results may be affected by chronic bacterial colonisation of the airways is uncertain. Although the study only included subjects without either a history of lower respiratory tract infection or evidence of bacterial infection as determined by microbiological culture, undetected bacterial airway colonisation in some smokers remains an important potential influence on neutrophil counts. Finally, when neutrophilic inflammation was assessed in terms of absolute counts, the differences between COPD and healthy subjects did not achieve significance although there was also a significant trend for counts to increase with advancing disease stage. This observation is in contrast to previous studies. ${ }^{32}{ }^{33}$ The counts correlated only weakly with airflow obstruction and not at all with any other lung function or HRCT parameter, suggesting that they are of limited value as indicators of COPD severity.

In conclusion, this study provides evidence that peripheral airways dysfunction is a key determinant of COPD severity and that airway lumen neutrophilia is associated with this dysfunction but is not associated with the overall extent of emphysema as determined by quantitative HRCT. These findings suggest that the study of proximal airway secretions is of limited value in identifying the pathological determinants of emphysema severity.

\section{ACKNOWLEDGEMENTS}

The authors thank the staff of the Histochemistry Research Unit, Division of Infection, Inflammation and Repair, University of Southampton for their assistance with sample analysis.

\section{Authors' affiliations}

R A O'Donnell, C Peebles, J A Ward, A Daraker, G Angco, S T Holgate,

D E Davies, D J Delany, S J Wilson, R Diukanovic, Respiratory Cell and Molecular Biology, Division of Infection, Inflammation and Repair, University of Southampton, Southampton General Hospital, Southampton SO16 6YD, UK

P Broberg, S Pierrou, J Lund, Department of Molecular Sciences, Respiratory and Inflammation Research Area, AstraZeneca R\&D Lund, 22187 Lund, Sweden

This work was funded by AstraZeneca.

\section{REFERENCES}

1 Cosio M, Ghezzo H, Hogg JC, et al. The relations between structural changes in small airways and pulmonary function tests. N Engl J Med 1978;298:1277-81.

2 Hale KA, Ewing SL, Gosnell BA, et al. Lung disease in long-term cigarette smokers with and without chronic air-flow obstruction. Am Rev Respir Dis 1984;130:716-21.

3 Finkelstein R, Fraser RS, Ghezzo H, et al. Alveolar inflammation and its relation to emphysema in smokers. Am J Respir Crit Care Med 1995; 152:1666-72

4 Leopold JG, Gough J. The centrilobular form of hypertrophic emphysema and its relation to chronic bronchitis. Thorax 1957;12:219-35.

5 Cosio MG, Hale KA, Niewoehner DE. Morphologic and morphometric effects of prolonged cigarette smoking on the small airways. Am Rev Respir Dis 1980;122:265-71.

6 Retamales I, Elliott WM, Meshi B, et al. Amplification of inflammation in emphysema and its association with latent adenoviral infection. Am J Respir Crit Care Med 2001;164:469-73.

7 Turato G, Zuin R, Miniati M, et al. Airway inflammation in severe chronic obstructive pulmonary disease: relationship with lung function and radiologic emphysema. Am J Respir Crit Care Med 2002;166:105-10.

8 Gevenois PA, De Vuyst P, Sy M, et al. Pulmonary emphysema: quantitative CT during expiration. Radiology 1996;199:825-9.

9 Gevenois PA, de Maertelaer V, De Vuyst P, et al. Comparison of computed density and macroscopic morphometry in pulmonary emphysema. Am J Respir Crit Care Med 1995; 152:653-7.

10 Keatings VM, Collins PD, Scott DM, et al. Differences in interleukin-8 and tumor necrosis factor-alpha in induced sputum from patients with chronic obstructive pulmonary disease or asthma. Am J Respir Crit Care Med 1996; 153:530-4

11 Saetta M, Turato G, Facchini FM, et al. Inflammatory cells in the bronchial glands of smokers with chronic bronchitis. Am J Respir Crit Care Med 1997; 156:1633-9.

12 O'Shaughnessy TC, Ansari TW, Barnes NC, et al. Inflammation in bronchial biopsies of subjects with chronic bronchitis: inverse relationship of CD8+ T lymphocytes with FEV 1 . Am J Respir Crit Care Med 1997; 155:852-7.

13 Knudson RJ, Standen JR, Kaltenborn WT, et al. Expiratory computed tomography for assessment of suspected pulmonary emphysema. Chest 1991;99:1357-66.

14 Soejima K, Yamaguchi K, Kohda E, et al. Longitudinal follow-up study of smoking-induced lung density changes by high-resolution computed tomography. Am J Respir Crit Care Med 2000;161:1264-73.

15 Eda S, Kubo K, Fujimoto K, et al. The relations between expiratory chest CT using helical CT and pulmonary function tests in emphysema. Am J Respir Crit Care Med 1997;155:1290-4.

16 Kubo K, Eda S, Yamamoto H, et al. Expiratory and inspiratory chest computed tomography and pulmonary function tests in cigarette smokers. Eur Respir $J$ 1999;13:252-6.

17 Miniati M, Filippi E, Falaschi F, et al. Radiologic evaluation of emphysema in patients with chronic obstructive pulmonary disease. Chest radiography versus high resolution computed tomography. Am J Respir Crit Care Med 1995; 151:1359-67.

18 American Thoracic Society. Standardization of spirometry-1987 update. Am Rev Respir Dis 1987; 136:1285-98.

19 Diukanovic R, Wilson JW, Lai CK, et al. The safety aspects of fiberoptic bronchoscopy, bronchoalveolar lavage, and endobronchial biopsy in asthma. Am Rev Respir Dis 1991;143:772-7.

20 Pauwels RA, Buist AS, Ma P, et al. Global strategy for the diagnosis, management, and prevention of chronic obstructive pulmonary disease: National Heart, Lung, and Blood Institute and World Health Organization 
Global Initiative for Chronic Obstructive Lung Disease (GOLD): executive summary. Respiratory Care 2001;46:798-825.

21 Louis $R$, Lau $L C$, Bron $A O$, et al. The relationship between airways inflammation and asthma severity. Am J Respir Crit Care Med 2000;161:9-16.

22 Holm S. A simple sequentially rejective multiple test procedure. Scand J Stat 1979;6:65-70.

23 Peleman RA, Rytila PH, Kips JC, et al. The cellular composition of induced sputum in chronic obstructive pulmonary disease. Eur Respir J 1999:13:839-43.

24 Muller NL, Staples CA, Miller RR, et al. "Density mask". An objective method to quantitate emphysema using computed tomography. Chest 1988;94:782-7.

25 Gelb AF, Schein M, Kuei J, et al. Limited contribution of emphysema in advanced chronic obstructive pulmonary disease. Am Rev Respir Dis 1993; 147:1157-61.

26 Gelb AF, Hogg JC, Muller NL, et al. Contribution of emphysema and small airways in COPD. Chest 1996;109:353-9.

27 Arakawa H, Webb WR. Expiratory high-resolution CT scan. Radiol Clin North Am 1998;36:189-209.
28 Kubo K, Eda S, Yamamoto H et al. Expiratory and inspiratory chest computed tomography and pulmonary function tests in cigarette smokers. Eur Respir J 1999;13:252-6.

29 Miller RR, Muller NL, Vedal S, et al. Limitations of computed tomography in the assessment of emphysema. Am Rev Respir Dis 1989;139:980-3.

30 Saetta M, Ghezzo H, Kim WD, et al. Loss of alveolar attachments in smokers. A morphometric correlate of lung function impairment. Am Rev Respir Dis 1985; 132:894-900.

31 Pare PD, Brooks LA, Bates J, et al. Exponential analysis of the lung pressurevolume curve as a predictor of pulmonary emphysema. Am Rev Respir Dis 1982;126:54-61.

32 Keatings VM, Jatakanon A, Worsdell YM, et al. Effects of inhaled and oral glucocorticoids on inflammatory indices in asthma and COPD. Am J Respir Crit Care Med 1997; 155:542-8.

33 Rutgers SR, Postma DS, ten Hacken NH, et al. Ongoing airway inflammation in patients with COPD who do not currently smoke. Thorax 2000;55:12-8.

34 Betsuyaku T, Nishimura M, Takeyabu K, et al. Neutrophil granule proteins in bronchoalveolar lavage fluid from subjects with subclinical emphysema. Am J Respir Crit Care Med 1999;159:1985-91.

\section{LUNG ALERT}

\section{No difference in mortality between low and high PEEP}

$\Delta$ The National Heart, Lung, and Blood Institute ARDS Clinical Trials Network. Higher versus lower positive end-expiratory pressures in patients with the acute respiratory distress syndrome. N Engl J Med 2004;351:327-36

$\mathrm{P}$ ositive end expiratory pressure (PEEP) during ventilation improves arterial oxygenation by recruiting alveoli, but it may cause circulatory depression and increase airway pressure and lung volumes resulting in ventilator induced lung injury from overdistension.

In acute lung injury and acute respiratory distress syndrome (ARDS), mechanical ventilation is critical for the survival of the majority of patients. Most patients with acute lung injury and ARDS have been treated with PEEP values of 5-12 $\mathrm{cm} \mathrm{H}_{2} \mathrm{O}$. In this study, 549 patients with acute lung injury and ARDS were randomised to receive either high PEEP ( 13.2 (3.5) $\mathrm{cm} \mathrm{H}_{2} \mathrm{O}$ ) or lower PEEP (8.3 (3.2) $\mathrm{cm} \mathrm{H}_{2} \mathrm{O}$ ). All patients received a tidal volume goal of $6 \mathrm{ml} / \mathrm{kg}$ predicted body weight and an inspiratory plateau pressure of $30 \mathrm{~cm} \mathrm{H}_{2} \mathrm{O}$ or less. Blood samples reflecting mechanisms of lung inflammation and injury (plasma interleukin-6, surfactant protein D, and intercellular adhesion molecule 1) were obtained before randomisation (day 0 ) and on day 3. The mortality rate from any cause was $24.9 \%$ in the lower PEEP group and $27.5 \%$ in the higher PEEP group. There were no changes in plasma levels of biological markers of inflammation and lung injury in either group.

The authors conclude that, in patients with acute lung injury and ARDS who receive mechanical ventilation with a tidal volume goal of $6 \mathrm{ml} / \mathrm{kg}$ predicted body weight and an end inspiratory plateau pressure limit of $30 \mathrm{~cm} \mathrm{H} \mathrm{H}_{2} \mathrm{O}$, clinical outcomes are similar whether lower or higher PEEP levels are used.

P Bhatia 